questionnaire concerning the establishment of a member-sponsored publishing company. It was nevertheless felt that members would not be willing to finance a scheme that did not have a strong probability of being profitable and giving a fair return on investment.

After this somewhat disheartening analysis it was gratifying to be able to record the number of positive comments received on Europhysics News which seems to have been favourably received throughout Europe.

\section{Conclusion}

It was, therefore, the unanimous decision of the Bulletin Committee to recommend to Council the continuation and improvement of Europhysics News whilst consideration is given to the whole question of communication between members of the EPS including a more detailed study of requirements, methods and means.

Two measures can greatly assist in the continuation and improvement of Europhysics News.

(1) The appointment of a permanent member of the Secretariat to be responsible for the collation and assembly of information which has until now depended largely upon voluntary help.

(2) The active participation of member societies in the editorial work of Europhysics News.

Other ways of lightening the load on those who have produced the journal so far will also be considered. Meanwhile Europhysics News goes on !

\section{Society News}

A donation has been received from Stichting Physica, Utrecht, The Netherland amounting to $10000 \mathrm{Sw}$. frs.

Personal gifts have been received from :

The Rev. Prof. James R. McConnell, Dublin, Ireland

Prof. Victor F. Weisskopf, Cambridge, Mass., USA

The following organisations have decided to join the European Physical Society as Associate Members :

Danfysik A.S., Jyllinge, Denmark

North-Holland Publishing Company, Amsterdam, The Netherlands

Taylor and Francis Limited, London, UK.

\title{
CERN Future Programme
}

The European Organization for Nuclear Research, the joint high energy physics research organization of twelve western European States, has been studying for more than seven years a major extension to its present facilities.

The existing laboratory of CERN straddles the Franco-Swiss border near Geneva. Research undertaken principally by visiting teams from the Universities and research centres of the Member States is centred upon the use of two particle accelerators : a proton synchro-cyclotron of 600 $\mathrm{MeV}$, which came into operation in 1957 , and a $28 \mathrm{GeV}$ proton synchrotron, which has been operating since 1959. Intersecting Storage Rings for colliding beam physics in association with the synchrotron are currently under construction and are due to come into service next year. The laboratory has built up an extensive array of particle detectors and these are being further extended.

An important committee of European physicists - the European Committee for Future Accelerators (ECFA) first recommended in 1963 to the CERN governing body (the Council) the construction of a proton accelerator of $300 \mathrm{GeV}$ energy. In the following year designs were evolved for such a machine and its laboratory facilities.

The accelerator was conceived as a "combined-function" machine (with the main magnets combining the functions of bending the beam and focusing it, the peak magnetic field being $12 \mathrm{kG}$ ). Several long straight sections with ejection points were foreseen resulting in a ring diameter of $2.4 \mathrm{~km}$ and several tangential beam lines of up to $5 \mathrm{~km}$ length set out round the circumference. Member States were asked to propose sites for a new laboratory to house the accelerator.

In 1967 ECFA reaffirmed its opinion that such an accelerator was necessary for the progress of high energy physics in Europe. Its report was accepted by Council and Member
States were asked to express their intentions in regard to their participation in such a project.

By the end of 1968 one Member State (the UK) had given a negative decision and six (Austria, Belgium, France, Germany, Italy and Switzerland) had agreed to participate on the understanding that their financial commitment would not be higher than had originally been expected. The programme was accordingly revised, restricting the initial energy and/or intensity and limiting the number of initial experimental areas to one. The programme definition refering to a laboratory centred on an accelerator of not less than $200 \mathrm{GeV}$ was agreed by Council in June 1969.

Difficulties then arose as to the choice of site and early this year the project seemed to have reached an impasse. As a result, the approval of government representatives was sought for alternative proposals to be submitted.

Meanwhile in the new design study of the accelerator (led by the newly appointed Director-designate of the project, J.B. Adams), which began in Spring 69 in collaboration with laboratories in the Member States, the emphasis was placed on flexibility in the approach to ultimate performance. The "missing magnet" concept was elaborated, whereby on a ring of fixed diameter, provision can be made, by omitting half the magnets at the beginning, for a doubling of the energy at a subsequent date. The functions of bending and focusing were separated and the main magnets were envisaged as operating at a peak field of $18 \mathrm{kG}$. Recent developments in superconducting materials also suggested the installation of higher field superconducting magnets at a later stage, should they prove technically feasible and economically viable.

The new proposal seeks to take advantage of these developments in design and technology, to attract all the Member States to join the project and, at the same time, to resolve the 
problem of the long term future of the existing Laboratory near Geneva. At the same time significant economies can result for the governments of Member States.

The proposal now before Council has a number of variants but in essence it is to build a $300 \mathrm{GeV}$ accelerator adjacent to the existing Laboratory, use the existing proton synchrotron as injector and one of the halls which had been destined for experiments with the existing synchrotron as the first experimental area of the new machine. The variants include the possibility of filling only half the ring with conventional magnets so that research could begin at $150 \mathrm{GeV}$ after five years (instead of one year later at $300 \mathrm{GeV}$ ) followed by the addition of superconducting magnets over the next three years so that research at 400 to $550 \mathrm{GeV}$ could begin in 1979 . The new money required for these programmes would be only two thirds of that previously calculated as being necessary were the machine to be built on a site removed from the present laboratory. A detailed study is now being undertaken so that the new project could get under way at the beginning of 1971 .

\section{Letter from the Board of the High Energy and Particle Physics Division}

In this crucial period for the future of high energy physics in Europe, when a change in the programme for the next generation of particle accelerators was being considered and proposals were being prepared, the Interim Board of the High Energy and Particle Physics Division of the EPS (A. Berthelot, R. H. Dalitz, W. Paul, P. Preiswerk, A. Zichichi) felt it had a duty towards the high energy physicists to express its view point. It felt that it would be useful to reiterate certain principles it considers essential to observe in order that the new pro- ject should fully meet the needs of research in the next decades.

The Board addressed the letter (dated 30 April 1970) which is reproduced below to the high energy physicists and the bodies involved in the decision taking :

"The Board of the High Energy and Particle Physics Division of the European Physical Society has learned with interest of the recent proposal to construct the future European accelerator on a site adjoining the present site of CERN-Meyrin.

It noted, however, that the documents so far made public do not permit the making of a valid judgement on this project, and therefore considers it its duty towards the European physicists to call to mind a certain number of principles which it seems necessary to respect if the effort put into the construction of this big machine is to be a profitable one in the realm of European research in the next decades. It thinks it desirable that the studies which would make it possible to judge whether the new project adheres to these principles should be made public at the earliest opportunity - if they are already available - or undertaken immediately, and their results published soon. In any case, these studies should be the subject of the widest possible discussion amongst interested physicists.

The principles which it seems necessary to respect are, at a minimum, the following :

(1) Any new project should maintain, in the realm of particle physics in Europe, a level of research facilities comparable to that which will exist outside Europe at the same time.

(2) Any new project should be constructed without bringing about a substantial reduction in the level of scientific exploitation previously foreseen for the installations already existing or being constructed at CERN-Meyrin. (3) Any new project should be set up on a site which takes account of the future, and reserves sufficient space for foreseeable future developments, with a safety margin for those which may come about in the thirty years during which this accelerator will be constructed and exploited.

(4) Any new project should foresee in its first stage a minimum of working equipment for the benefit of experimental research. It is indispensable that the financial provisions should be drawn up with this in mind, and in particular it must be remembered that it will probably no longer be possible in the future, as was sometimes the case in the past, to ask for complementary national contributions to construct certain equipment."

It can be noted with satisfaction that after the discussions which have taken place with the high energy physicists, the proposal which is now put forward to the CERN Council and its Member States takes into account most of the principles expressed in the above letter.

It is important that this new programme goes through without too much delay. It can be hoped that the broad and active participation of the European high energy physicists will result in a successful project. Europe may therefore retain the possibility of continuing in this field of fundamental research in a position to make substantial contributions to our understanding of the physics of elementary particles and to the general development of international collaboration.

At the June session of the CERN Council, Professor Willibald Karl Jentschke was appointed to succeed Professor Bernard Gregory as Director General of CERN. Professor Jentschke currently heads a five-man Directorate at the DESY Laboratory in Hamburg, Federal Republic of Germany. He will take office in January 1971 for a period of four years. 